$$
\text { CONF-9606116--71 }
$$

\title{
Confinement of Ignition and Yield on the National Ignition Facility
}

\author{
M. Tobin, V. Karpenko, D. Foley, \\ A. Anderson, A. Burnham, T. Reitz, \\ J. Latkowski, and T. Bernat
}

\section{RECEIVED \\ AUG 164996 \\ OSTII}

This paper was prepared for submittal to the American Nuclear Society 12th Topical Meeting on the Technology of Fusion Energy

Reno, NV

June 16-20, 1996

June 14, 1996

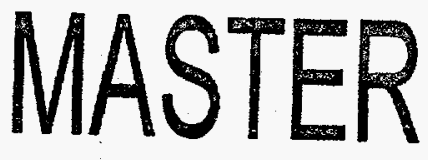

This is a preprint of a paper intended for publication in a journal orproceedings. Since changes may be made before publication, this preprint is made available with the understanding that it will not be cited or reproduced without the permission of the author.

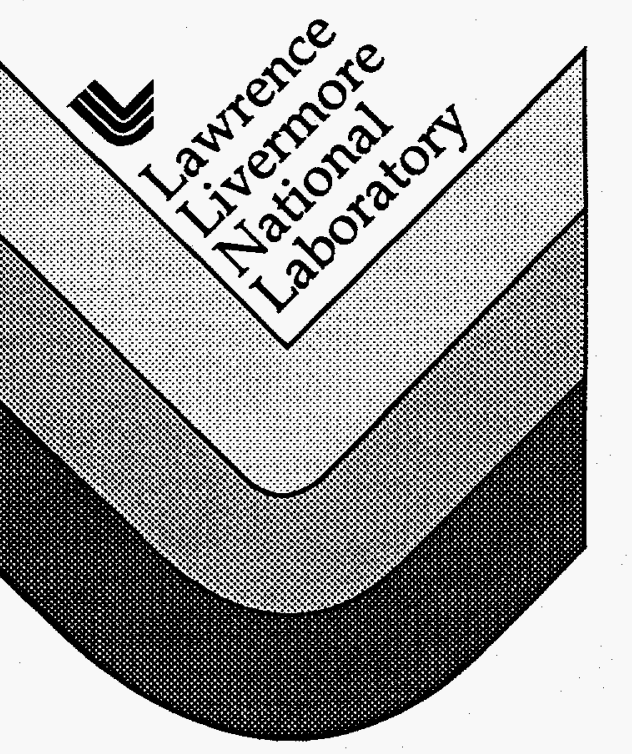




\section{DISCLAIMER}

This document was prepared as an account of work sponsored by an agency of the United States Government. Neither the United States Government nor the University of California nor any of their employees, makes any warranty, express or implied, or assumes any legal liability or responsibility for the accuracy, completeness, or usefulness of any information, apparatus, product, or process disclosed, or represents that its use would not infringe privately owned rights. Reference herein to any specific commercial product, process, or service by trade name, trademark, manufacturer, or otherwise, does not necessarily constitute or imply its endorsement, recommendation, or favoring by the United States Government or the University of California. The views and opinions of authors expressed herein do not necessarily state or reflect those of the United States Government or the University of California, and shall not be used for advertising or product endorsement purposes. 


\section{DISCLAIMER}

Portions of this document may be illegible in electronic image products. Images are produced from the best available original document. 


\title{
CONFINEMENT OF IGNITION AND YIELD ON THE NATIONAL IGNITION FACILITY
}

\author{
M. Tobin, V. Karpenko, D. Foley, A. Anderson, A. Burnham, T. Reitz, J. Latkowski, T. Bernat \\ Lawrence Livermore National Laboratory \\ P.O. Box 5508, L-481 \\ Livermore, CA 94550 (510/423-1168)
}

\section{ABSTRACT}

The National Ignition Facility Target Area and Experimental Systems has reached mid-Title I design. Performance requirements for the Target Area are reviewed and design changes since the Conceptual Design Report are discussed. Development activities confirm a 5-m radius chamber and the viability of a boron carbide first wall. A scheme for cryogenic target integration with the NIF Target Area is presented.

\section{INTRODUCTION}

The Department of Energy is proposing to construct and activate into operation the National Ignition Facility (NIF) by the year 2002 to embark on a program to achieve ignition and modest gain in the laboratory. The preferred site is the Lawrence Livermore National Laboratory (LLNL). The NIF Project is currently in the Title I design phase.

The NIF will consist of a $1.8-\mathrm{MJ}, 0.35-\mu \mathrm{m}$ laser with 192 independent beamlets. This represents a 50 -fold increase in laser energy over the Nova laser at LLNL. The main laser pulse will be -3 ns and 500 TW of power. Target experiments will be positioned and contained in a $5-\mathrm{m}$ radius, $10-\mathrm{cm}$ thick sphere. Diagnostics are primarily positioned around the mid-plane of the sphere for data collection. The NIF Target Area is designed to safely contain up to an annual yield of $1200 \mathrm{MJ}$ distributed among shots ranging from $\sim 100 \mathrm{~kJ}$ to $20 \mathrm{MJ}$, with as many as 350 shots producing significant $\mathrm{D}-\mathrm{T}$ neutron yield each year. In addition, as many as 850 non-yield shots may also be conducted in the same year, depending on the quantity of induced radioactivity and access requirements to support the desired shot rate. Although indirect drive inertial confinement fusion (ICF) is the baseline, direct drive experiments will also be possible after a conversion time. ${ }^{1}$

The neutron, $x$-ray, debris, shrapnel, and unconverted light environments created by these experiments introduce unique conditions requiring innovative design solutions. Solutions to these issues include in-chamber laser light absorbers, a first wall facing material designed for x-ray protection, and frost/ice protection of close-in components (e.g., target positioner). Confidence in overall Target Area system performance will be developed by evaluating the ability of the various sub-systems, once established to meet design requirements, to interact safely, affordably, and with low risk to meet the required shot rate.

This paper summarizes Target Area performance criteria, an experimental plan, targets and associated emissions/effects, concepts for introducing cryogenic targets, and general discussion of operations issues. The Target Area mid-Title I design is summarized.

\section{TARGET AREA PERFORMANCE CRITERIA}

The Target Area has certain Primary Criteria and Functional Requirements that shall be met by the design. These include the capability to:

- field both cryogenic and non-cryogenic targets

- contain 1200-MJ annual yield

- conduct 50 shots of 20-MJ yield in one year

- withstand a 45-MJ maximum credible yield

- operate in both classified and unclassified modes

- conduct non-yield experiments every four hours

- achieve a vacuum of $<10^{-5}$ Torr

- position and align a target to within $50 \mu \mathrm{m}$.

Additionally, the Target Area will not preclude the ability to:

- add a second target chamber for weapons physics or radiation effects testing

- conduct direct drive experiments

- conduct radiation effects testing, which includes allowing laser irradiation of distributed target arrays. ${ }^{2}$

Public safety has been documented in a Programmatic Environmental Impact Statement and elsewhere. 3,4,5 Occupational safety will follow DOE Orders N441.1 and 420.1. Radiation shielding design shall limit doses to $1 / 10$ th the values specified in 10 CFR 835 , currently 500 mrem per year. Maximum tritium inventory will be $500 \mathrm{Ci}$. Shielding will be designed to limit doses in occupied areas of the NIF to $\leq 30 \mathrm{mrem}$, and immediately exterior to the facility to $\leq 50 \mathrm{mrem}$. 


\section{EXPERIMENTAL PLAN}

The overall experimental plan for the facility has yet to be finalized and is currently under development. $6 \mathrm{We}$ use the plan developed for indirect drive ignition to base Target Area design, since the attainment of up to fifty 20-MJ yields may be the most severe design conditions.

The NIF indirect drive experimental plan for achieving fusion ignition is comprised of four stages?:

- Startup experiments will consist of shots to validate the laser performance, including synchronization, smoothing, pointing, and power balance with temporally shaped pulses, and shots needed to activate diagnostics.

- Hohlraum tuning experiments will consist of shots in which beam phasing is adjusted to minimize the time-dependent asymmetry in $x$-ray drive.

- Cryogenic pre-ignition experiments will consist of shots that include low-convergence and high-convergence implosions with dudded fuel. These experiments will allow close-in diagnostics to obtain data for a detailed comparison with design calculations.

- Ignition experiments will consist of shots designed to map out the gain curves, where yields of $100 \mathrm{~kJ}$ to perhaps $20 \mathrm{MJ}$ will be achieved.

Therefore, the introduction of targets that produce yield and gain will occur over time. Figure 1 suggests a possible time-phased increase in target yield capability that the NIF will achieve. This has important ramifications on the initial design features for the NIF. The phased implementation of NIF design features to provide radiation safety in the presence of neutrons may include, at the appropriate level of neutron emission on NIF, the following features:

- carbon holders for the debris shield, KDP lenses, focus lenses, the vacuum windows, and final mirrors

- $\mathrm{C}$ in place of $\mathrm{Al}$ in the Final Optics Assembly (FOA)

- C shaft target-positioner shaft instead of $\mathrm{Al}$ or steel

- plan for interior neutron shielding for the FOA

- shielding inside the target positioner shaft

- $\mathrm{Al}$ in place of steel mirror structural supports in the Target Bay

- shielded plugs installed on all unused chamber ports

- bolts, motors, windings, actuators, bellows, etc. replaced when necessary after neutron activation

- cryogenic support materials made from $\mathrm{Al}_{2} \mathrm{O}_{3}$ in lieu of stainless steel

- doors up to six feet thick to protect access ways into the Target Bay from neutron leakage.

\section{TARGETS, EMISSIONS, AND EFFECTS}

A range of targets have been considered as to their $x$-ray, debris, neutron, and shrapnel emissions and their associated effects. (Shrapnel is defined as any material below the vaporization point, for example, including droplets.) These targets include disks, empty hohlraums, and cryogenic hohlraums. The effects of 'shine-shields,' placed on certain targets to alleviate the effects of unconverted light on diagnostics, have also been considered. Modeling is on-going at LLNL, University of Wisconsin, University of California Berkeley, CEA, and SRI International. Associated experimentation to explore issues raised by modeling is on-going using the LLNL Nova laser, the CEA Phebus laser, gas guns at SRI International, the OSL laser at LLNL, and the $\mathrm{CO}_{2}$ cleaning test stand and laser damage testing facility at LLNL. ${ }^{8-15}$

Conclusions from these efforts include:

- $\mathrm{A} \mathrm{B}_{4} \mathrm{C}$ first wall provides a 5-m chamber radius with adequate $\mathrm{x}$-ray protection, e.g., acceptable damage for a 20-MJ shot with peak $x$-ray fluences of $2.65 \mathrm{~J} / \mathrm{cm}^{2}$.

- The form of the $\mathrm{B}_{4} \mathrm{C}$, currently hot-pressed plates, can possibly be the potentially more economical thermally-sprayed $\mathrm{B}_{4} \mathrm{C}$, pending successful development.

- Standard sol-gel anti-reflection coatings on debris shields have limited survivability to $\mathrm{x}$ rays $\left(\leq 0.25 \mathrm{~J} / \mathrm{cm}^{2}\right)$ and may result in no coating on the target-side of this optic (4\% loss of laser light results; consideration is being given to placing the debris shield at the Brewster's angle, $55^{\circ}$, to avoid this loss).

- $\mathrm{A} \mathrm{B}_{4} \mathrm{C}$ first wall, either hot-pressed or plasmasprayed, survives repeated irradiations of $x$ rays and repeated cleanings with the $\mathrm{CO}_{2}$ pellet process with acceptable erosion, approximately a few $\mu \mathrm{m}$ per year.

- Some significant amounts of particulate $\mathrm{B}_{4} \mathrm{C}$ debris on the debris shields appear to 'self-clean,' potentially extending their in-chamber time.

- Access to the Target Bay for limited times after a 20-MJ shot appear possible after 2 to 4 days, depending on the required tasks and their duration.

- The use of concrete collimators between the switchyard and the Target Bay appears to adequately suppress neutron leakage.

- Shrapnel generated from cryogenic targets will be highly directional, and a debris shield coating that can be stripped may provide significant protection to the bare silica substrate. 
- Use of a large, frost-coated 'mini-chamber' inside the NIF chamber may have some benefit to alleviating the effects of large yield shots, and will be considered for implementation on NIF.

\section{TARGET AREA OPERATIONS}

The conduct of cryogenic target experimental campaigns will need to consist of a series of low-yield shots consecutively fielded in order to make the most efficient use of both the calibrated target diagnostics and the personnel who travel to the NIF to conduct the experimental campaign. Therefore, we set as a possible goal (not design requirement) the ability to conduct three cryogenic shots in a single day, for two days back-to-back (e.g., six cryo-shots in 48 consecutive hours), of $-100-\mathrm{kJ}$ yield. In addition, in the same week, we set a goal to be able to conduct a single shot of 5- to $20-\mathrm{MJ}$ yield. This will amount to a total of seven cryogenic shots in a single week. Finally, we set the goal that the number of no-yield shots in that same week be from three to nine, depending on the maximum yield achieved. It is recognized that later in NIF's operational life, there may be a demand to try to consolidate the 5- to 20-MJ shots as well. Therefore, we also set the goal that two 5- to 20-MJ shots can be conducted in the same week if no $100-\mathrm{kJ}$ shots are conducted. Three possible weekly NIF operating scenarios can be described as follows:

(1) no-yield (1.0- to 2.2-MJ laser shots) -18 in six consecutive days;

(2) no-yield (1.0- to 2.2-MJ laser shots)-nine in three consecutive days;

$100-\mathrm{kJ}$ yield - six in two consecutive days;

5- to 20-MJ yield-one with 2-4 days of 'stay-out' time, depending on the actual yield; and

(3) no-yield (1.0- to 2.2-MJ laser shots)—nine in three consecutive days;

5- to 20-MJ yield - - two with 4-8 days of 'stay-out' time, depending on actual yield.

It must be stressed that these are operational scenarios represent a conservative approach to satisfying the shot rate requirements, and are goals for operations, not requirements. Full analysis of the ability to meet these schedules will not be complete until the end of Title II design, since not only detailed design parameters that are evolving must be known, but also decisions about operational needs must be set. These are challenging goals to meet. However, it is also recognized that the flexibility for consolidation of shots in experimental campaigns may be very beneficial to NIF operations. Consolidation of shots could result in increased or extended maintenance periods between weeks of intensive NIF experimentation.

\section{FIELDING CRYOGENIC TARGETS}

The detailed physical design of a cryogenic indirect drive target has yet to be completed. However, enough is known to identify an envelope of impacts and required support capabilities to encompass any of the various technologies being considered for implementation of cryogenic target experiments.

The minimum annual number of shots is $\sim 600$, although NIF design will not preclude the ability to achieve a maximum number of shots per year (both with and without yield), which is $\leq 1200$. Three shots per day must be conducted, using $\sim 250$ days during the year, to achieve 600 shots. The capsules need to be maintained at $18 \mathrm{~K} \pm 0.1 \mathrm{~K}$. The total number of cryogenic shots per year will be $\leq 335$, set by tritium throughput limitations. Each target, regardless of the yield expected, is assumed to contain equimolar $\mathrm{D}-\mathrm{T}$, with $0.15 \mathrm{mg} \mathrm{T}$ per indirect drive target $(1.5 \mathrm{Ci})$. As confidence and understanding in the relationships among target yield, target design, target fabrication, target fielding, and laser energy are established, capsules may be designed to give less than the possible yield through such techniques as non-equimolar mixtures or reducing the laser energy.

The maximum number of cryogenic shots conducted in a single week will be seven. Therefore, NIF will have the capability to receive and store up to seven indirect-drive transport cryostats at a single time. Each target is transported in a refrigerator-sized enclosure that contains enough cryogen to allow the target temperature to be adequately controlled for up to 48 hours without external support. Once the targets from a shipment are received into $\mathrm{NIF}$, each refrigerator will be hooked up to $\mathrm{LN}$ and LHe tanks so that the targets can be temperature-controlled indefinitely. The location of the target receipt room is on the second floor of the diagnostics building. The transport assembly is estimated to weigh $\leq 300 \mathrm{~kg}$ and will be manipulated on wheels. It will enter the Target Bay and be lifted to the target room floor by a hoist. There will be diagnostics capabilities integrated into the transport cryostat to allow some determination of target readiness.

When a target is needed for a cryogenic experiment, it will be lifted to the third floor, and rolled to the target inserter-positioner. There, up to one hour or more may be needed to re-establish an acceptable fuel layer on the target. To provide the high quality final ice layer inside the capsule, certain special techniques are being considered. These may include $B$-layering with He cooling, B-layering with conduction cooling, joule heating, IR enhanced B-layering, and RF joule heating enhanced B-layering. It is possible, perhaps even likely, that the final fuel preparation will take place inside the chamber. The 
equipment required to perform these functions can be mounted on the chamber using existing planned ports and diagnostics manipulators. The actual cryostat will be detached from the housing (that provided its thermal protection and transportation) outside the target inserter breech. The target will have a cryogenic (LHe) shroud to protect it during this transfer process. The cryostat will have enough cryogen to keep the target cold for several hours while it is unhooked from the transport cryostat cart cryogen and reconnected to the cryogenic target inserter. The whole target assembly is then pushed into the chamber once this interlock is evacuated. The chamber must be reduced from $\sim 10^{-5}$ to $\sim 10^{-6}$ Torr at this time to prevent unacceptable frost build-up on the windows of the target (unless double windows, which would prevent frost build-up on the window, are adopted for target design). Final surface treatment of the fuel then takes place, followed by final target positioning, final diagnostics' alignment, and target-beam alignment to $50-\mu \mathrm{m}$ tolerance; then, after the shroud has been removed and returned to its housing in the wall or on the target positioner, the laser system is fired.

The size of the equipment package that supports the target inside the chamber is yet to be finalized. However, scoping calculations have determined a size for the purposes of assessing impacts of cryogenic operations. This cryostat size is $2 \mathrm{~m}$ long, an average of $0.5 \mathrm{~m}$ in diameter, and weighs $150 \mathrm{~kg}$. It contains 100 liters of liquid $\mathrm{He}$ an average of $50 \mathrm{~cm}$ from the target, and 50 liters of liquid $\mathrm{N}_{2}$ an average of $1 \mathrm{~m}$ from the target. If these cryogens were released into the chamber, the resulting pressure increase would be only $0.25 \mathrm{~atm}$.

The cryostat is exposed to intense neutron irradiation and would require holding in a radiological storage area for $1-2$ days for a $100-\mathrm{kJ}$ shot before refurbishment and reuse if it is constructed of stainless steel. Levels are much higher for a 20-MJ shot and indicate the need to minimize the use of stainless steel components in the design.

\section{OVERVIEW OF TARGET AREA DESIGN}

Facility. The Target Bay is bordered by six-foot thick walls of concrete of conventional construction. There are six interior concrete floors, each one-foot thick, that provide access to chamber systems, and stability for the chamber system. The concrete floors contains 1 at.\% boron. Beam entrances are bordered by concrete collimators that extend three feet into the Target Bay and 3-8 feet into the switchyard to suppress neutron leakage into the Laser Bay. The roof of the Target Bay is 4.5 feet thick. The walls of the switchyard are 3.7 feet thick, and the roof is 2 feet thick (see Fig. 2).
Target Chamber. The chamber is 10-m diameter, 10-cm thick Al5083 and has been assigned a 7- $\mu \mathrm{m}$ stability requirement. The oil-free vacuum system is designed to reach $670 \mu$ bars within two hours and has been moved to the pedestal location to accommodate the direct drive option. There are a total of four 1.3-m cryo-pumps. There are $\sim 150$ chamber penetrations including: 75 diagnostics ports, 72 laser beam ports (four beamlets per port) for both direct and indirect drive, three ports for the target positioners and shroud assemblies, and a single large waist port for Radiation Sciences experiments. Diagnostics implementation has changed little since the Conceptual Design Report (CDR). 15 All ports have flanged port covers to accommodate neutron shielding. Beam turning mirrors and final optics assemblies are placed on horizontal planes for ease of access. The chamber is mounted on a four-tier pedestal with equatorial lateral damping and support (see Fig. 3). Approximately $1200 \mathrm{~B}_{4} \mathrm{C}$ panels (either hot-pressed or plasma-sprayed $\mathrm{Al}$ ), each $-2500 \mathrm{~cm}^{2}$, will be mounted on the chamber wall to provide first wall protection to $\mathrm{x}$-ray emissions. Chambershielding cost optimization for the NIF Conceptual Design Report selected concrete for minimum cost for shielding effectiveness and inflammability. A 40-cm thickness was selected based on assumptions of operational requirements. The increase of annual yield from $385 \mathrm{MJ}$ to $1200 \mathrm{MJ}$, and increasing clarification of operational needs for access will necessitate re-assessment of the required thickness. The incompatibility of $\mathrm{Al}$ and concrete will also require a design solution.

Unconverted light absorbers. Unconverted light absorbers made of $\mathrm{Cu}$-doped phosphate glass, covered with fused silica, have been shown to withstand $>50 \mathrm{~J} / \mathrm{cm}^{2}$ fluence of $3 \omega$ light without damage. 17 The predicted peak levels are bounded by $30 \mathrm{~J} / \mathrm{cm}^{2} .{ }^{7} \mathrm{X}$-ray exposures of fused silica have shown that the predominant mechanism for material removal is vaporization. This will be experienced for shots of $\sim 5 \mathrm{MJ}$ or larger, and for shots where $1.8 \mathrm{MJ}$ of laser light is directed onto a disk with high conversion efficiency. Laser interferometry of the exposed surface reveals a near optical flatness. ${ }^{8}$ Performance of the light absorbers in the presence of debris is unknown and will be examined experimentally.

Beam Transport. Current design of final optics employs wedging in the focus lens to disperse unconverted $1 \omega$ and $2 \omega$ light away from the laser entrance hole. An alternative method is to use a specially developed diffraction grating to disperse the unconverted light uniformly over the first wall, while allowing improved beam focusing and reducing laser damage concerns for the focus lens and debris shield. A no-wedge focus lens design demands greater horizontal 
separation of the $2 \times 2$ beamlet bundles. An alternate layout has been established that would allow conversion to this improved unconverted light scheme after the requisite diffraction grating is developed, even if this is after NIF is built. The no-wedge beam transport layout still accommodates the direct drive option.

Target Positioner. The positioner requires: 6- $\mu \mathrm{m}$ positional accuracy, $6-\mu \mathrm{m}$ stability (vibrational and thermal), 50- $\mu \mathrm{m}$ placement repeatability, three translational degrees of freedom, two rotational degrees of freedom, and the ability to support a $150-\mathrm{kg}$, $2 \mathrm{~m} \times 50 \mathrm{~cm}$ target transport cryostat. The positioner supports both non-cryogenic as well as cryogenic targets. The shaft of the target positioner is made from composite so that there is no extended delay in implementing cryogenic operations on NIF, as previously planned, as an aluminum positioner would experience substantial activation $(\sim 1 \mathrm{rem} / \mathrm{hr}$ at one day after a $100-\mathrm{kJ}$ shot $)$, and present radiological hazard concerns for the activity of target loading and insertion. Consideration is being given to protecting the tip of the inserter with an ice-on-foam scheme to suppress condensable ablated material and strong shocks to the positioner.

Structural Design. Structural supports must provide a stable platform of less than $\pm 7-\mu \mathrm{m}$ translation and $\pm 0.7-\mu \mathrm{rad}$ rotation, and manage the random vibration thermal environments. The design must also choose lowactivation materials and maintain Class- 100 cleanliness in optical enclosures of the final optics assemblies. Mirrors are supported from structures mounted on the horizontal floors. Total integrated vibration and structural analysis and thermal evaluation is on-going. The potential need for embedded water cooling in facility walls and/or floors for thermal management is being studied.

Final Optics Assemblies (FOA). The FOA's require lateral stability of $7 \mu \mathrm{m}$, window stress of $<500 \mathrm{psi}$, $5 \times 10^{-5}$ Torr vacuum, $\sim 20-\mu \mathrm{rad}$ positioning for conversion crystals, resolution of motion $\sim 2 \mu \mathrm{rad}$, $\pm 5 \mathrm{~cm}$ focal adjustment, Class- 100 cleanliness, and thermal control of conversion crystals to $\pm 0.1^{\circ} \mathrm{C}$. The assembly consists of an integrated optics module (IOM), final optic cell, debris shield system, $3 \omega$ calorimeter chamber, vacuum isolation valve, and thermal control system (see Fig. 3). As a change since the CDR, the IOM incorporates a $1 \omega$ vacuum window relieving the focus lens of this task and placing the KDP crystals in a vacuum. Plans call for debris shields to be changed as frequently as weekly. Rapid change-out ( $<1 \mathrm{hr}$ for four shields) will be aided by a semi-automated enclosure, frameless shields, and development of a gripper. The FOA will be prototyped in FY 97.
Environmental Protection Systems (EPS). The EPS is located in the basement of the diagnostics building, below grade. Housed in this room is a mobile, robotic manipulator that provides several remote functions for the target chamber interior: $\mathrm{CO}_{2}$ cleaning of the first wall and unconverted light absorbers; removing/installing first wall panels; removing/installing FOA port covers; and providing a man-lift. A 15-ton-capacity hydraulic lift is used to raise the robot into the chamber. A more detailed description of $\mathrm{CO}_{2}$ cleaning is treated elsewhere. 15

\section{CONCLUSIONS}

The Title I Design for the NIF Target Area and Experimental Systems is progressing toward conclusion in October 1996. Among key issues awaiting resolution are: design impacts of phased implementation of neutron mitigation features, the need for thermal management with active cooling, optimum $\mathrm{CO}_{2}$ cleaning parameters, improved debris shield change-out rate, and selection of hot-pressed or thermal-spray first wall panels.

This work was performed under the auspices of the U.S. Department of Energy by Lawrence Livermore National Laboratory under contract No. W-7405-Eng-48.

\section{REFERENCES}

1. M. Tobin, "Target Area Design Issues for Implementing Direct Drive on the National Ignition Facility," this conference.

2. "National Ignition Facility Functional Requirements and Primary Criteria Revision 1.4, February 1996," Lawrence Livermore National Laboratory, Livermore, California, NIF-LLNL-93-058, L-15983-3.

3. Draft Programmatic Environmental Impact Statement for Stockpile Stewardship and Management, Volume III. DOE/EIS-0236 (January 8, 1996).

4. S. Brereton et al., "Safety Analysis of the National Ignition Facility," this conference.

5. National Ignition Facility Draft Preliminary Safety Analysis Report, Lawrence Livermore National Laboratory, Livermore, California, UCRL-ID-123759 DR, NIF-LLNL-96-238, L-21729-1 (May 31, 1996).

6. Department of Energy, Office of the National Ignition Facility, Facility Use Plan of the National Ignition Facility (in press).

7. National Ignition Facility Conceptual Design Report, Volume 2: Design Basis and Requirements, Lawrence Livermore National Laboratory, Livermore, California, UCRL-PROP-117093 Vol. 2, NIFLLNL-94-113, L-16973-1 (May 1994). 
8. A. Anderson et al., "X-ray Emission from National Ignition Facility Indirect Drive Targets," this conference.

9. A. Anderson et al., "Modeling and Experiments of $X$-ray Ablation of National Ignition Facility First Wall Materials," this conference.

10. A. Burnham et al., "Development and Evaluation of First Wall Materials for the National Ignition Facility," this conference.

11. J. Latkowski and M. Tobin, "The Selection of Concrete Compositions for Use in the National Ignition Facility Target Area," this conference.

12. R. Tokheim et al., "Calculating the Shrapnel Generation and Subsequent Damage to First Wall and Optics Components for the National Ignition Facility," this conference.

13. D. Schirmann et al., "Target Area Conceptual Design Issues of the French Laser MegaJoule Facility (LMJ)," this conference.

14. R. Peterson, "Response of the National Ignition Facility First Wall Materials to Target $\mathrm{X}$ rays and Debris," this conference.

15. J. Scott et al., "The Mini-Chamber: An Advanced Protection Concept for the National Ignition Facility," this conference.

16. T. Reitz et al., Utilization of the $\mathrm{CO}_{2}$ Pellet Blasting Process for the National Ignition Facility," this conference.

17. M.D. Cable, J.D. Kilkenny, R.A. Lerche, M.B. Nelson, M.J. Moran, T.C. Sangster, J.E. Trebes, R.E. Turner, and T.W. Phillips, Diagnostic Development at LLNL for the National Ignition Facility, Lawrence Livermore National Laboratory, Livermore, California, UCRL-JC-?? (June 1996).

18. D. Milam et al., "High Fluence Tests of Beam Dumps," Lawrence Livermore National Laboratory, Livermore, California, Internal Memorandum (August 18, 1995).

19. H. Streckert et al., "Conceptual Design of a Low Activation NIF Target Chamber and Components," this conference. 


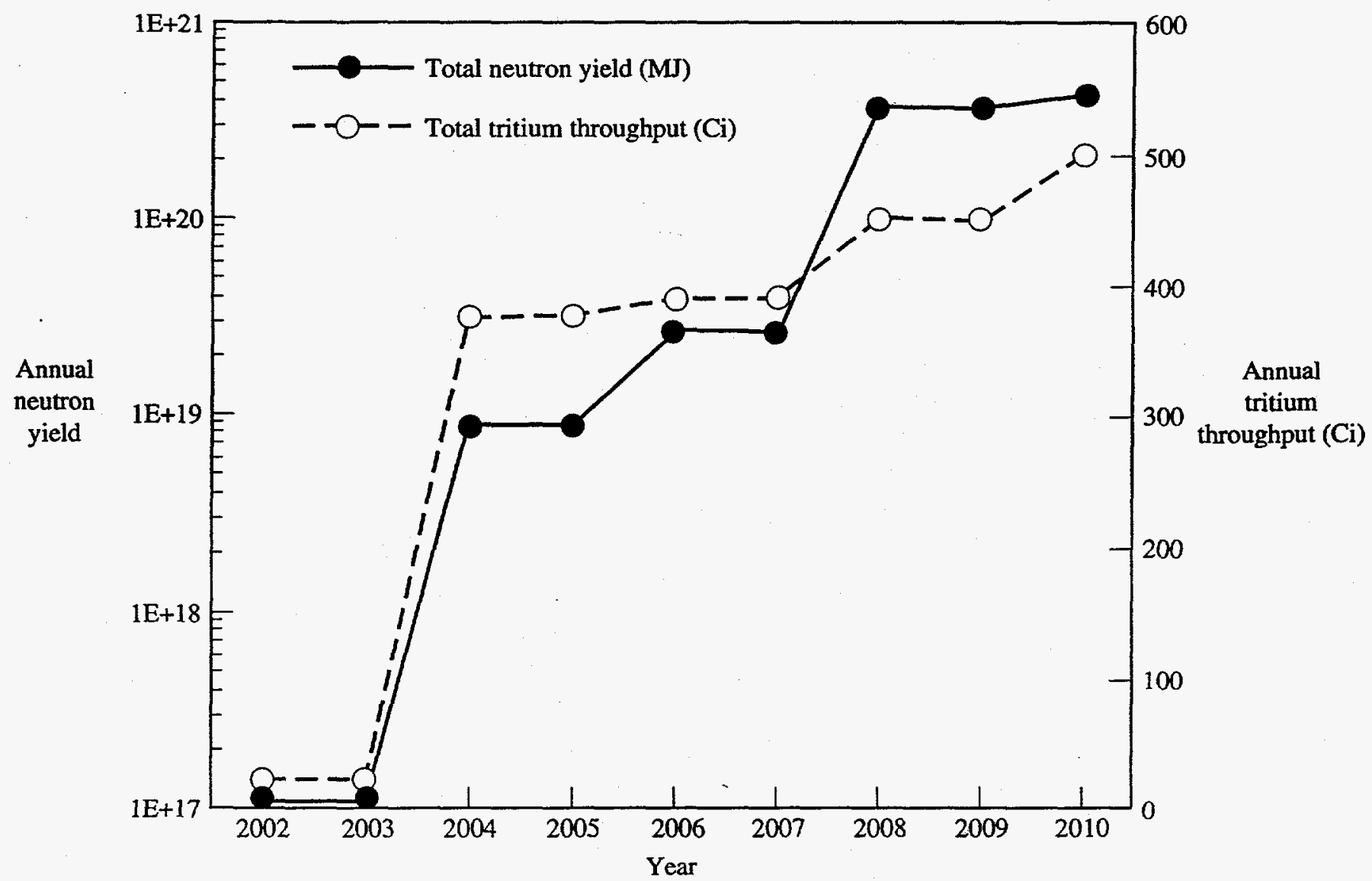

Fig. 1. A projected schedule for yield targets on NIF. The first two years consists of one hundred $10^{15}$ neutron shots per year. The next two years assume 250 shots of up to $100 \mathrm{~kJ}$. The next two add ten $5 \mathrm{MJ}$ shots per year. Finally, the last three indicate fifty 20-MJ shots in the year. At this time the maximum annual yield of $1200 \mathrm{MJ}$ may be possible. For indirect drive operations, the annual throughput does not approach the facility limit of $1750 \mathrm{Ci}$ per year. Direct drive targets, with 10 times more tritium per target, will challenge this limit with only $\sim 120$ shots in a year. 


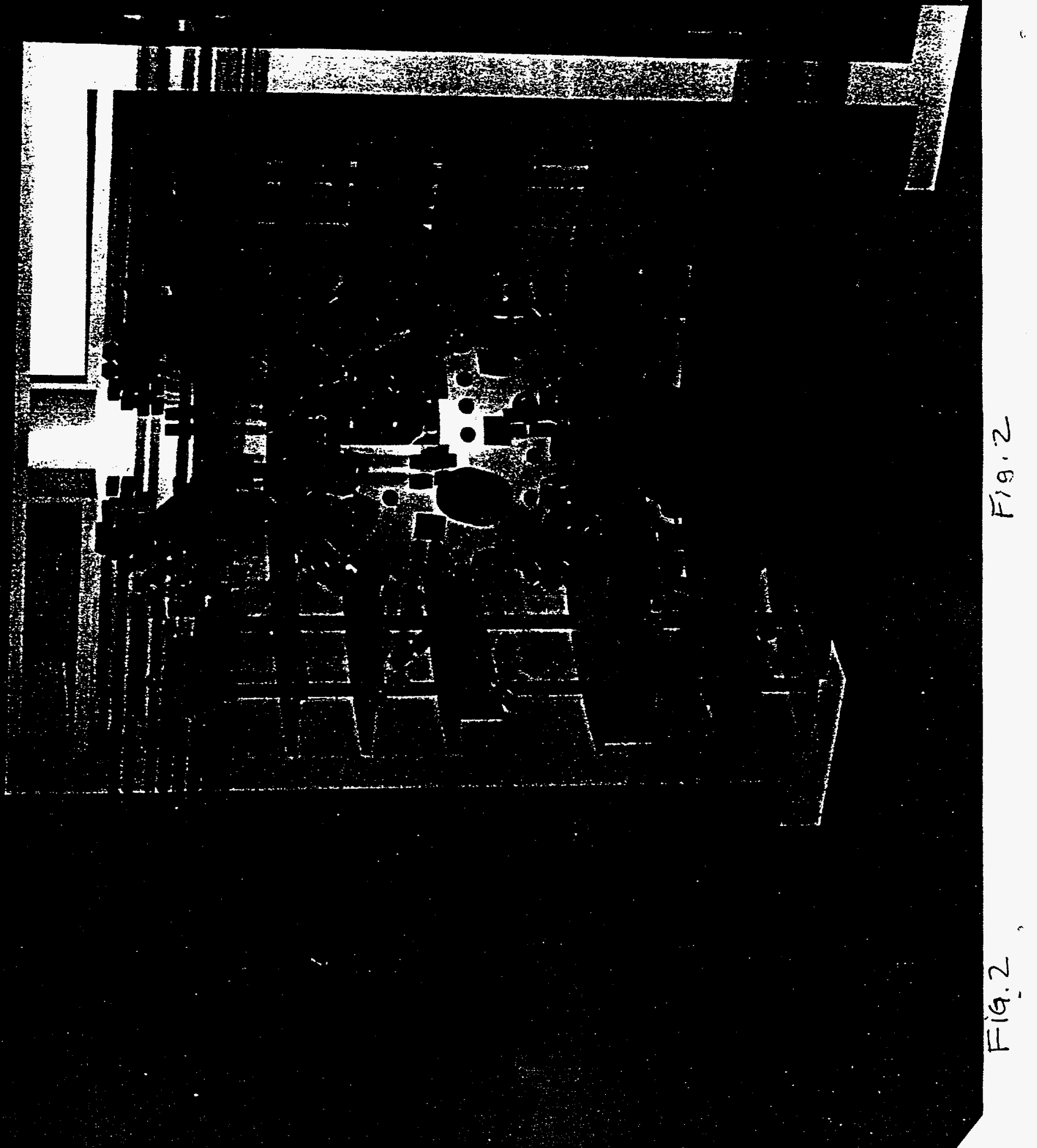


The chamber is supported by a new pedestal that houses the vacuum system

Final optics assemblies

Direct drive ports

Diagnostic ports

Vacuum plenum

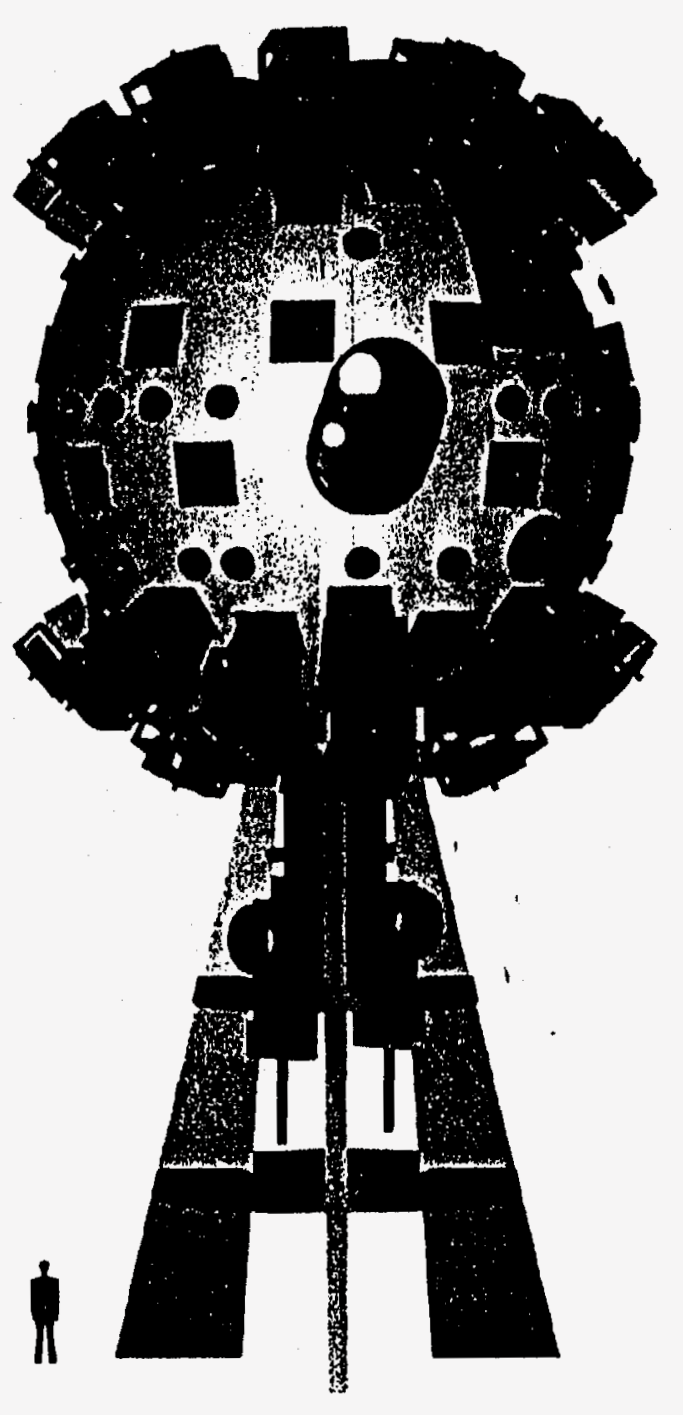

Indirect drive ports

$400 \mathrm{~mm}$ shielding

Radiation effects user port

$1295 \mathrm{~mm}$ cryopumps

Pedestal 